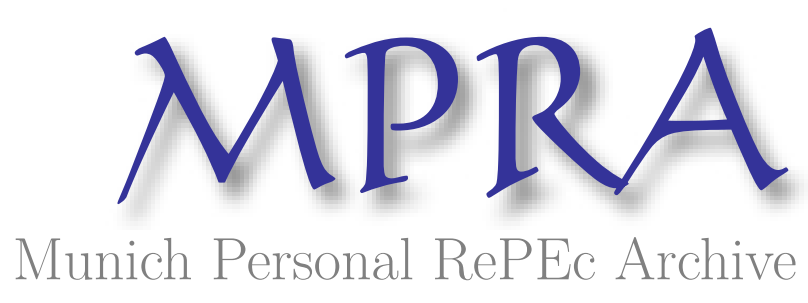

\title{
COVID-19 and Covered Deposits
}

Van Roosebeke, Bert and Defina, Ryan

1 March 2022

Online at https://mpra.ub.uni-muenchen.de/112098/

MPRA Paper No. 112098, posted 03 Mar 2022 04:37 UTC 
Ryan Defina

IADI Research Unit

ryan.defina@iadi.org
Bert Van Roosebeke

IADI Research Unit

bert.vanroosebeke@iadi.org

\title{
COVID-19 AND COVERED DEPOSITS
}

\author{
Executive Summary
}

Understanding and managing the risks associated with COVID-19 is a priority area of concern for deposit insurers on a global basis. This paper investigates quarterly growth rates of covered deposits and finds statistically significant evidence that during the first six quarters of the pandemic, quarterly growth of covered deposits has shifted upwards by $1.5 \%$-points. On a per-quarter basis, we find evidence of statistically significant increases in the second half of 2020.

Results are based on a September 2021 member survey conducted by the International Association of Deposit Insurers in conjunction with the State Corporation Deposit Insurance Agency (Russian Federation).

\section{Introduction and purpose}

The COVID-19 pandemic has challenged practically all dynamics underpinning economic activity for nearly two years now. Along the way, it has placed the global financial system under considerable strain ${ }^{1}$, and exposed numerous vulnerabilities in global supply chain management. The global financial safety net has also been challenged within the context of near-unprecedented disruption to the activities of corporates, imposition of constraints on labour movement and consumption, and utilisation of wide-ranging fiscal stimulus to support the economy. Such fiscal policy responses have undoubted affected businesses and households, and particularly the incentives for households to save more in time of uncertainty. Of particular interest to deposit insurers is whether this resulted in more savings growth and covered (insured) deposit growth in the financial system.

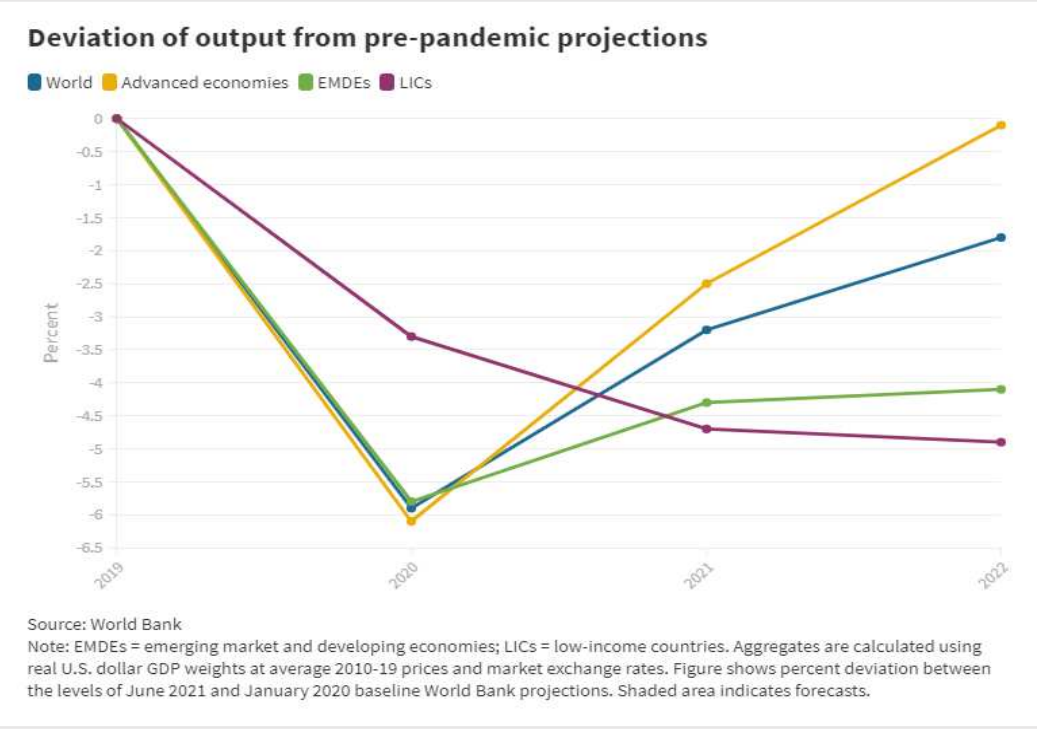

World Bank research ${ }^{2}$ indicates that 2020 global output was $6 \%$ lower than prepandemic projections, and broadly based among all major regions. This deviation remained in the $2-5 \%$ range throughout the first half of 2021, with only advanced economies expected to revert back to output levels consistent with pre-pandemic projections by 2022. The gap in economic recovery between advanced economies and emerging economies is expected to widen in 2022, suggesting that emerging economies will be disproportionately (adversely) affected by the pandemic.

\footnotetext{
${ }^{1}$ FSB (2021)

${ }^{2}$ World Bank (2021)
} 
While macroeconomic indicators have highlighted a broad-based downturn in the global economy, preliminary assessments have also sighted areas of success for financial sector standard setters. There is increasing evidence to suggest that - facilitated by broad fiscal support - rules put in place in response to the 2008 Global Financial Crisis (GFC) have increased overall resilience in financial systems, reducing the potential adverse effects of COVID-19 on the global economy, and may aid recovery over the medium term. In mid-2021, The Basel Committee for Banking Supervision released a report noting that "higher quality capital and liquidity levels required by the reforms helped banks absorb the significant impact of Covid-19 shock; and, the banking system would have faced greater stress during this period had the reforms not been adopted and implemented". ${ }^{3}$

A survey of IADI Members was conducted in September 2021 in collaboration with the Deposit Insurance Agency (DIA) Russia. Submissions were received from deposit insurers in 40 jurisdictions, all of which are IADI Members. ${ }^{4}$ The extent of population representativeness for the survey sample is explored in the Appendix. The survey was commissioned with the intention of quantifying trends in deposit insurance throughout the pandemic period, largely determined as commencing 2020Q1. Information for the three years proceeding is also collected to enable intervention analysis, with a focus on whether changes in key metrics could be correlated with the pandemic's evolution over time.

This paper is the second one covering the pandemic. A previous IADI Survey Brief titled Impact of the COVID-19 Pandemic on Deposit Insurance examined initial high-level impacts of the COVID-19 pandemic on global deposit insurance systems. It was however too early to appraise whether certain impacts on deposit insurers were sustained over the medium term, nor did it attempt to explore more detailed policy considerations.

The key research question that is explored in this paper is whether there is sufficient evidence to conclude that flows in covered deposits increase throughout (or throughout an interval of) the pandemic above-and-beyond pre-pandemic levels.

\section{Summary of survey results}

\section{Extent and evolution of COVID-19 restrictions}

The survey operated within a reference period whereby economic activity had been constrained by authorities in an attempt to address public health concerns. Such restrictions varied among jurisdictions, but clear patterns were nevertheless identified. A framework was constructed which categorised all restrictions (or 'lockdowns') into 'Full / substantial lockdown', 'Partial lockdown' and 'No significant lockdown'. ${ }^{6}$

\footnotetext{
${ }^{3}$ BCBS (2021)

${ }^{4}$ Submissions were received from the Albanian Deposit Insurance Agency, Albania; Fundo de Garantia de Depósitos, Angola; Agency of Deposit Compensation, Belarus; Bulgarian Deposit Insurance Fund, Bulgaria; Canada Deposit Insurance Corporation, Canada; Autorité des marchés financiers, Canada (Québec); Central Deposit Insurance Corporation, Chinese Taipei; Fondo de Garantías de Instituciones Financieras, Colombia; State Agency for Deposit Insurance and Bank Resolution, Croatia; Deposit Insurance Fund, Czech Republic; Corporación del Seguro de Depósitos, Ecuador; Instituto de Garantía de Depósitos, El Salvador; Hellenic Deposit and Investment Guarantee Fund, Greece; Hong Kong Deposit Protection Board, Hong Kong SAR; National Deposit Insurance Fund of Hungary, Hungary; Interbank Deposit Protection Fund / Fondo Interbancario di Tutela dei Depositi, Italy; Jamaica Deposit Insurance Corporation, Jamaica; Deposit Insurance Corporation of Japan, Japan; Jordan Deposit Insurance Corporation, Jordan; Kazakhstan Deposit Insurance Fund, Kazakhstan; Kenya Deposit Insurance Corporation, Kenya; Korea Deposit Insurance Corporation, Korea; Deposit Protection Agency of the Kyrgyz Republic, Kyrgyz Republic; Instituto para la Protección al Ahorro Bancario, Mexico; Deposit Insurance Corporation of Mongolia, Mongolia; Deposit Protection Fund, Montenegro; Norwegian Banks' Guarantee Fund, Norway; Palestine Deposit Insurance Corporation, Palestine; Fund Deposit Insurance, Paraguay; Philippine Deposit Insurance Corporation, Philippines; Deposit Insurance Agency, Russian Federation; Saudi Arabian Monetary Authority, Saudi Arabia; Fondo de Garantia de Depositos de Entidades de Credito, Spain; Deposit Protection Agency, Thailand; Deposit Insurance Corporation, Trinidad and Tobago; Fonds de Garantie des Depots Bancaires, Tunisia; Savings Deposit Insurance Fund, Turkey; Federal Deposit Insurance Corporation, United States; Deposit Insurance of Vietnam, Vietnam; Deposit Protection Corporation, Zimbabwe.

${ }^{5}$ Defina (2021)

${ }^{6}$ The following classification was developed for the survey: Full / substantial lockdown - Legal requirement for most of the population to stay at home and to leave only on an exceptional basis, e.g. seeking medical treatment, to purchase essential goods, etc; Partial lockdown - Legal requirement for some sectors to not operate (e.g. non-essential businesses) and/or imposition of other significant constraints on commerce domestically; No significant lockdown - Most of the economy is able to function as usual, with some accommodations made e.g. mask and/or vaccine requirements. 2021Q4 constitutes an expectation among survey respondents rather than an observation.
} 
Results suggest that, on average across all responding jurisdictions, the most severe restrictions were in place in 2020Q2. A gradual (and consistent) reduction of restrictions by approximately $10 \%$ every quarter then presents until the present day. As of September 2021, almost $80 \%$ of jurisdictions are expected to have lifted major restrictions they had previously put in place by the end of 2021Q4. Not only do restrictions constrain consumption possibilities, but they may also correlate with the provision of fiscal stimulus to support households and businesses. Both factors have the potential to impact savings, and hence the magnitude of deposit taking.
Evolution of COVID-19 Restrictions

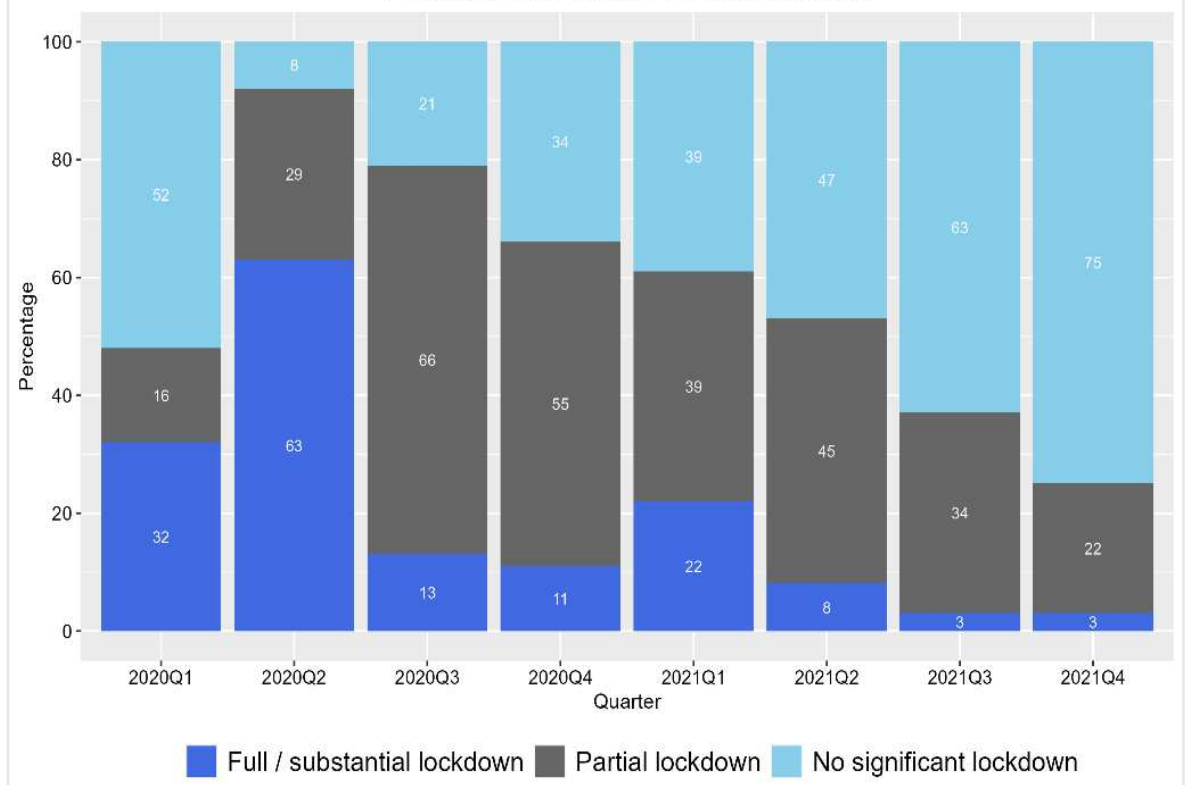

\section{Growth in total covered deposits}

The stock of covered deposits in a jurisdiction is of fundamental importance to deposit insurers as it forms their primary exposure, and as such, the predominant source of risk to their balance sheet.

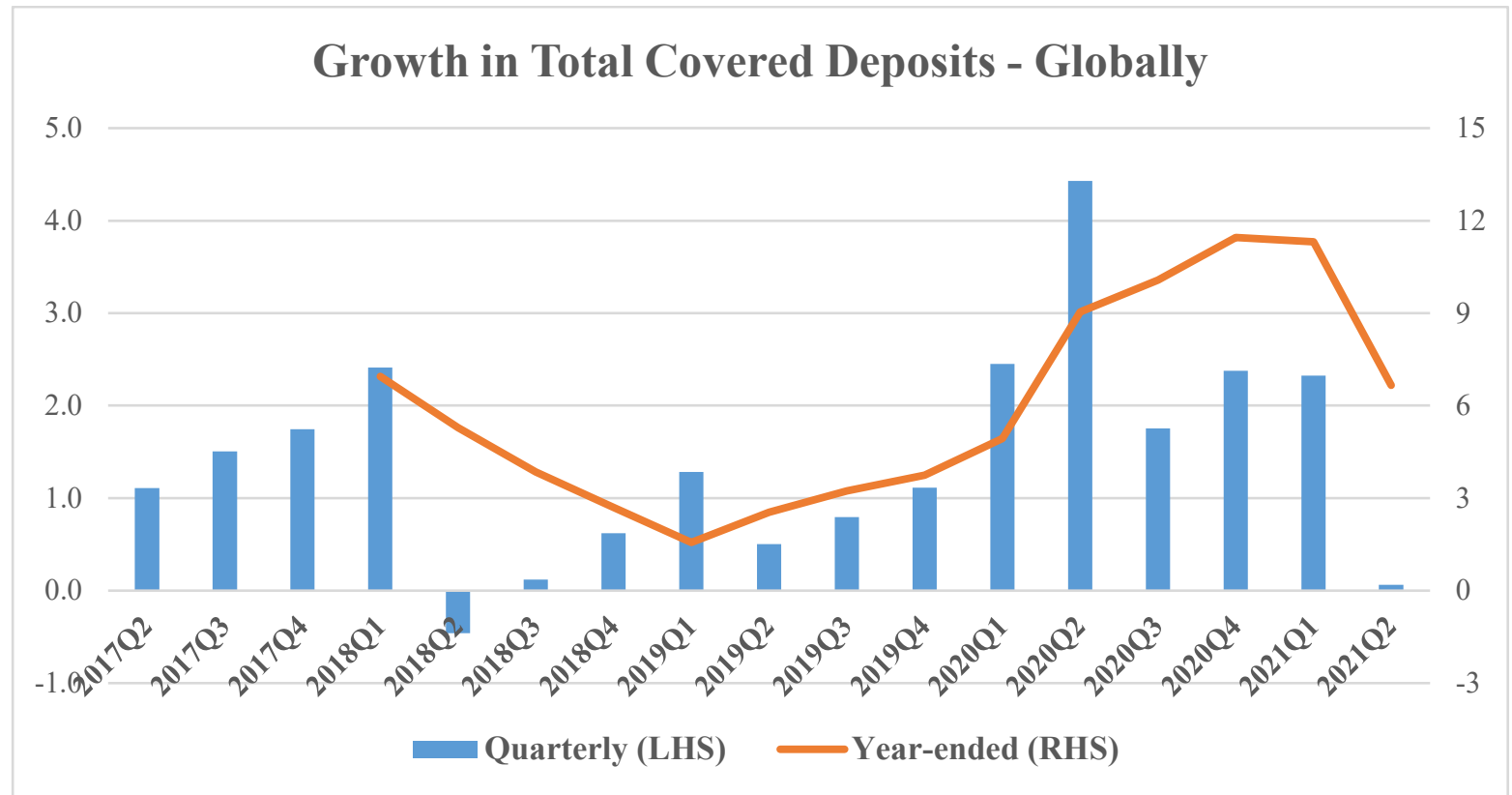

Based on data collected in this survey, the average quarterly growth rate in total covered deposits was $1.0 \%$ in the prepandemic period 2017-2019, and 2.2\% in the pandemic period covering 2020-2021Q2. ${ }^{7}$ In year-ended terms, comparing a quarter with the same quarter in the preceding year, this amounted to $3.7 \%$ in the period $2017-2019$ and $8.9 \%$ between 2020 and 2021Q2. This suggests that the advent of COVID-19 corresponded with an approximately doubling of quarterly growth. The sharpest increase in quarterly growth occurred in $2020 \mathrm{Q} 2$, with nearly $4.5 \%$. This period coincided with both the broad-based imposition of lockdowns (or other constraints on movement) which particularly disrupted retail consumption and engagement in vocational activities, along with provision of (in many cases,

\footnotetext{
${ }^{7}$ Covered deposits data has been reviewed and imputation methods (such as 'last observation carried forward' and linear interpolation) utilised to fill gaps in the respondent-level time series. Such gaps emerge due to the fact that not all respondents collect data on a quarterly basis, among other reasons. Growth rates are computed on the basis of aggregated survey responses, which where all converted into US Dollar using quarterly exchange rates. Hence, large survey participants (e.g., US) heavily influence the total sample.
} 
unprecedented levels of) fiscal stimulus. Figures indicate that as of end 2021, growth is returning to pre-pandemic levels, however, this isn't necessarily a reliable indicator of future outcomes as considerable COVID-related uncertainty remains. It is also unclear whether and to what extent lingering supply chain bottlenecks ${ }^{8}$ and emerging inflationary pressures will have any significant effect on covered deposits.

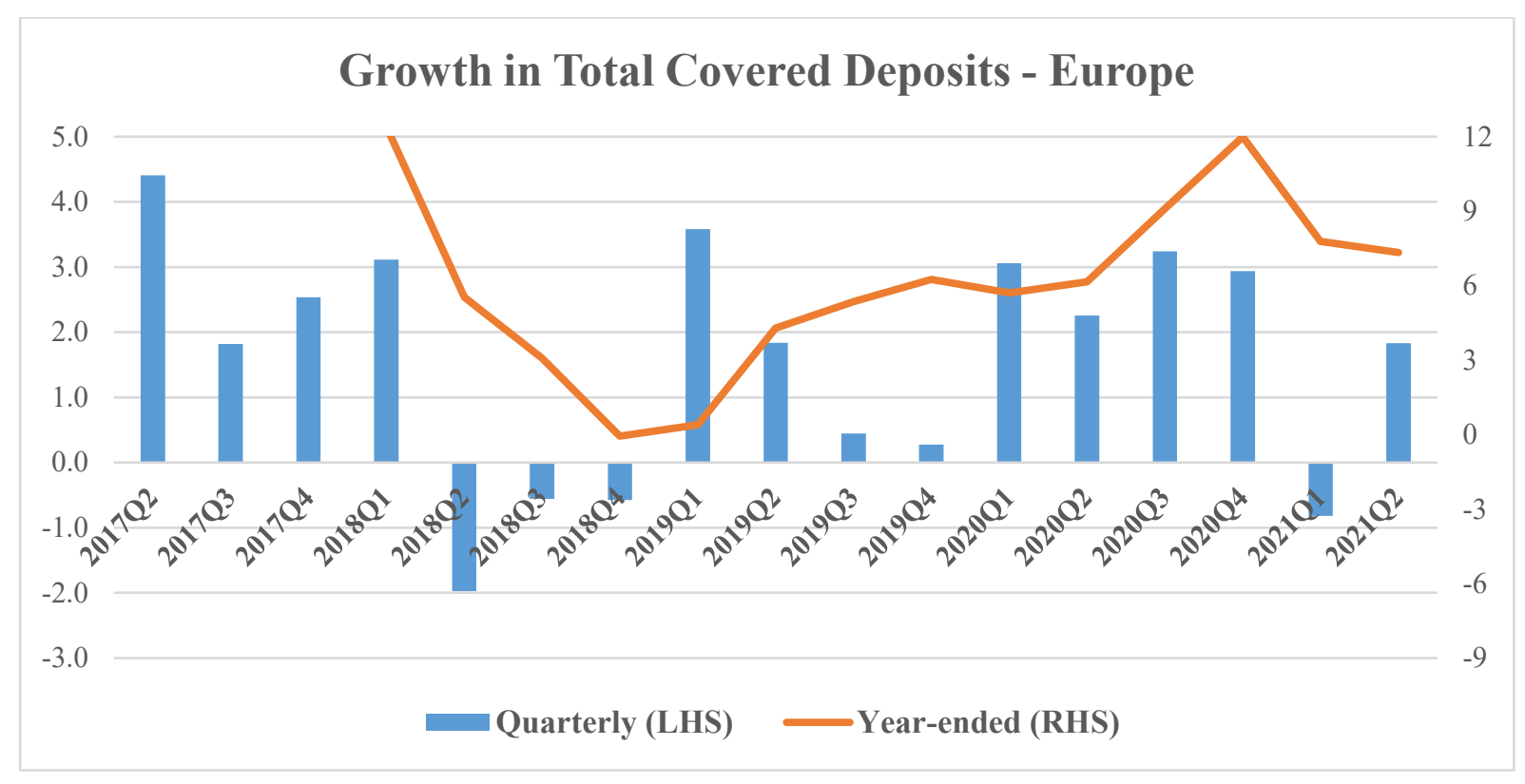

One hypothesis being explored by the international community is whether increases in covered deposits are limited to continental Europe and other relatively higher income jurisdictions. ${ }^{9}$ While quarterly growth in $2020 \mathrm{Q} 1$ among European banks is approximately half a percentage point higher than global figures, it is just over two percentage points lower in 2020Q2 (the highest growth period). Covered deposit growth does appear slightly more consistent in European banks, smoothed throughout the pandemic period around the $2 \%$ mark rather than experiencing any significant peaks. Nevertheless, with the exception of 2020Q2, the European figures don't generally behave too differently from their nonEuropean counterparts.

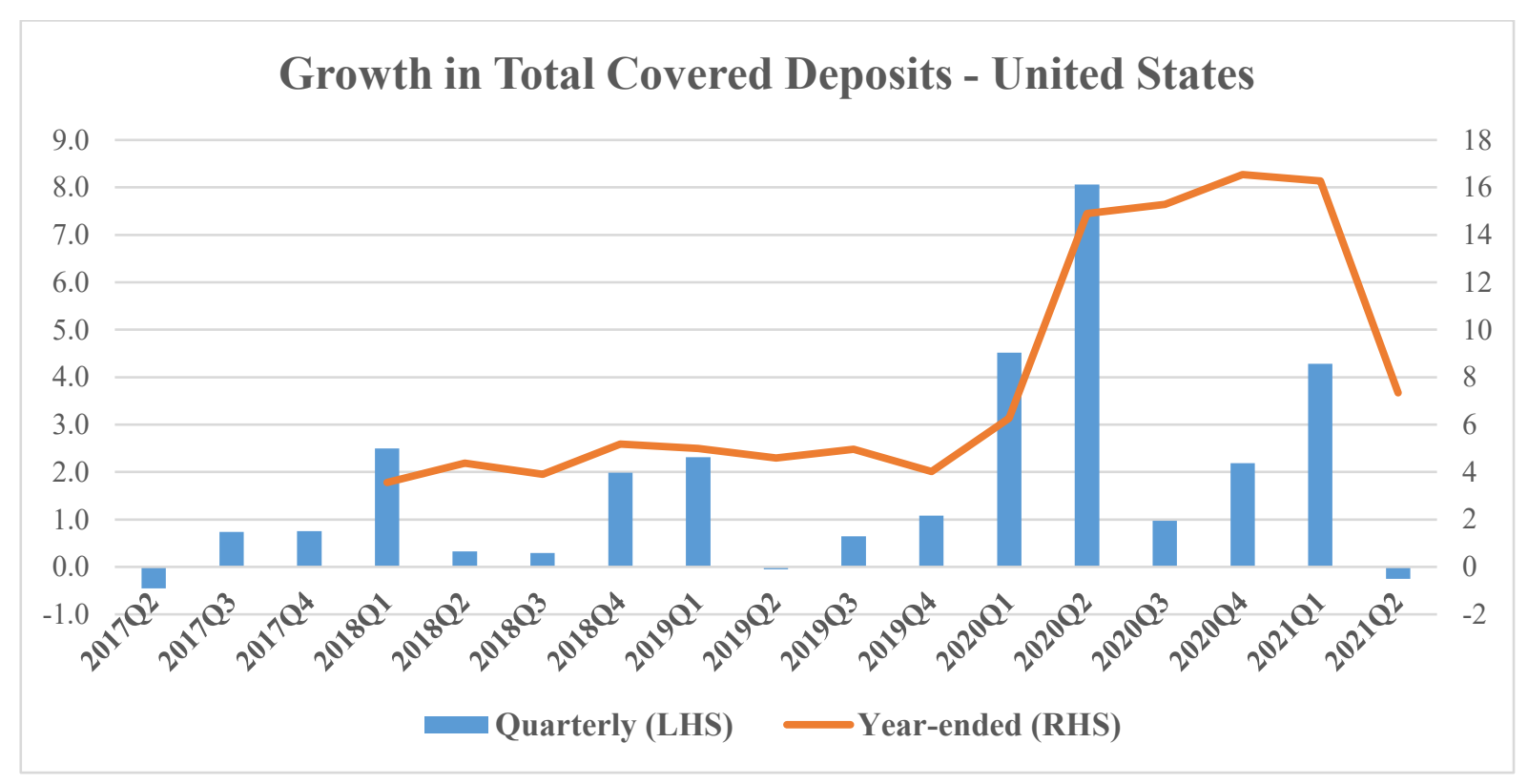

\footnotetext{
${ }^{8}$ Rees \& Rungcharoenkitkul (2021)

${ }^{9}$ The relatively sizable welfare state observed on the continent, and correspondingly significant fiscal response, has led analysts to suggest that European households would be more liquid than their non-European counterparts. Hence, offering more accommodating economic conditions that enable savings to be accrued.
} 
Deposits attributed to American banks constitute over one third of all deposits collected in this IADI survey. ${ }^{10}$ It is therefore not surprising to observe that growth rates among American banks tend to drive global figures. This is particularly the case for the substantial growth measured in 2020Q2.

At least for the US, and over an even longer time horizon, it is clear that the pandemic period has corresponded with comparatively large increases in deposits of FDIC-insured institutions. ${ }^{11}$ Notably, these exceed figures observed during, and shortly after the 2008 GFC.

\begin{tabular}{|l|l|}
\hline Quarterly Change in Deposits \\
\hline All FDIC-Insured Institutions \\
$\$$ Billions \\
1,400 \\
1,200 \\
1,000 \\
800 \\
600 \\
400 \\
200 \\
\hline 0 \\
-200 \\
\hline 2000 20009201020112012201320142015201620172018201920202021 \\
Note: Date labels are centered under the first quarter of each year. Data starts in third quarter 2007.
\end{tabular}

Table One presents the percentage of survey respondents whose quarterly growth in covered deposits exceeded various thresholds in each quarter. This offers some perspective on the distribution of jurisdiction-level growth rates over time and enables some high-level benchmarking to be conducted.

TABLE ONE: PERCENTAGE OF SURVEY RESPONDENTS EXCEEDING COVERED DEPOSIT GROWTH THRESHOLDS, IN PERCENTAGE POINTS (PPT)

\begin{tabular}{|c|c|c|c|c|c|c|}
\hline Threshold & $2020 \mathrm{Q} 1$ & $2020 \mathrm{Q} 2$ & $2020 \mathrm{Q} 3$ & $2020 \mathrm{Q} 4$ & $2021 \mathrm{Q} 1$ & $2021 \mathrm{Q} 2$ \\
\hline $2 \mathrm{ppt}$ & $53 \%$ & $76 \%$ & $42 \%$ & $58 \%$ & $29 \%$ & $37 \%$ \\
\hline $5 \mathrm{ppt}$ & $13 \%$ & $29 \%$ & $11 \%$ & $18 \%$ & $5 \%$ & $11 \%$ \\
\hline $10 \mathrm{ppt}$ & $5 \%$ & $8 \%$ & $8 \%$ & $5 \%$ & $0 \%$ & $5 \%$ \\
\hline
\end{tabular}

\footnotetext{
${ }^{10}$ While the case study is not provided, Japanese banks (another major contributor to the global stock of covered deposits) have exhibited similar trends to those of their American counterparts.

${ }^{11}$ Source: FDIC (2021)
} 


\section{Methodology}

Of particular interest is the manner in which covered deposits have evolved throughout the COVID-19 pandemic. The survey collection enabled a time series to be constructed. However, the figures contain statistical variation and any insights generated may be confounded by extraneous factors. ${ }^{12}$ In order to isolate the potential effect of this COVID-19 period on covered deposits, a number of econometric models are constructed. Each seeks to account for different factors, and when considered as a whole, paint an overall picture of how covered deposits have evolved throughout the pandemic. Changes in the growth of covered deposits typically result from:

Excesses in household and/or corporate liquidity, that is ultimately saved. This is usually caused by unexpected increases in financial inflows e.g. provision of additional fiscal stimulus such as one-off payments, state-subsidised wage supplements, mortgage/loan moratoria, and contractionary monetary policy.

Reductions in consumption and/or investment due to perceived uncertainty or lack of spending possibilities. This may result from downturns in overall economic activity, a reduction in consumer/business sentiment, or from lockdowns and similar restrictions reducing spending and travelling possibilities. Such an environment may yield a sudden reduction in household consumption and/or business investment until confidence in economic fundamentals is restored. This can also include the adoption of bearish positions in equity markets which may generate adverse momentum effects.

\subsection{Modelling framework}

The period in which COVID-19 has been prevalent is partitioned into six non-overlapping quarters - 2020Q1, 2020Q2, 2020Q3, 2020Q4, 2021Q1, 2021Q2. These form the basis for exploring any evolving deposit dynamics throughout the period. ${ }^{13}$

A fixed effects modelling framework is implemented to explain changes in the quarterly growth rates of covered deposits over time. ${ }^{14}$ Fixed effects seek to account for jurisdiction-specific factors, both COVID-19 related and otherwise. These include differential COVID-19 policy responses and other legislative or structural factors.

The various models utilise the following notation:

$\boldsymbol{d}_{\boldsymbol{i}, \boldsymbol{t}} \quad$ covered deposits of DI $\mathrm{i}$ in quarter $\mathrm{t}$

$\boldsymbol{\alpha}_{\boldsymbol{i}} \quad$ fixed effect of DI i

$\mathbf{\Omega} \quad$ first order autoregressive effective of one-quarter-lagged covered deposits

$\boldsymbol{\delta}_{\boldsymbol{i}, \boldsymbol{k}} \quad$ indicator variable for COVID-quarter k of DI i

$\boldsymbol{\beta}_{\boldsymbol{k}}$ effect of COVID-quarter $\mathrm{k}$ above and beyond the average pre-COVID quarterly growth rate in covered deposits $\boldsymbol{\delta}_{\boldsymbol{i}}^{\{t \geq 2020 Q 1\}} \quad$ indicator variable for the time period exclusively from 2020Q1 onwards of DI i

$\boldsymbol{\beta}$ effect of COVID period (2020Q1 onwards) on quarterly growth rate in covered deposits above and beyond the average pre-COVID rate

$\boldsymbol{G D} \boldsymbol{P}_{\boldsymbol{i}, \boldsymbol{t}}$ gross domestic product per capita of DI $\mathrm{i}$ in quarter $\mathrm{t}^{15}$

$\boldsymbol{\rho} \quad$ linear effect of GDP i.e. average percentage points increase in the quarterly growth rate of covered deposits every quarter

$\boldsymbol{F} \boldsymbol{L}_{\boldsymbol{i}, \boldsymbol{t}} \quad$ indicator variable corresponding to full lockdown of DI $\mathrm{i}$ in quarter $\mathrm{t}$

\footnotetext{
${ }^{12}$ Potentially many omitted variables may drive bias in the parameter estimates. This is acknowledged as a trade-off in pursuing model parsimony. ${ }_{13} 2021$ Q3 and 2021Q4 are mostly beyond the scope of this paper. The survey was run in 2021Q4 where most 2021Q3 and 2021Q4 data points were yet to be made available. It is acknowledged that sample sizes are relatively small and may hence limit the potential of models to determine statistically significant effects.

${ }^{14}$ Model parameter estimates are generated via maximum likelihood estimation techniques - see Croissant (2020) for further details.

${ }^{15}$ Data is expressed in USD in 2010 prices, is annualised, and lagged by one reporting period.
} 
$\zeta_{1} \quad$ linear effect of full lockdown i.e. average percentage points increase in the quarterly growth rate of covered deposits every quarter

$P \boldsymbol{L}_{i, t} \quad$ indicator variable corresponding to partial lockdown of DI i in quarter $\mathrm{t}$

$\zeta_{2} \quad$ linear effect of partial lockdown i.e. average percentage points increase in the quarterly growth rate of covered deposits every quarter

$\boldsymbol{\epsilon}_{\boldsymbol{i t}} \quad$ error term for DI i in quarter t i.e. variation not explained by any of the aforementioned factors

Model A tests for the effects of the pandemic period 2020Q1 - 2021Q2 as a whole:

$$
\begin{gathered}
\log _{e} d_{i, t}-\Omega \log _{e} d_{i, t-1}=\alpha_{i}+\beta \delta_{i}^{\{t \geq 2020 Q 1\}}+\epsilon_{i t} \\
\alpha_{i} \sim N\left(0, \tau_{i}^{2}\right) \& \epsilon_{i t} \sim N\left(0, \sigma^{2}\right)^{16}
\end{gathered}
$$

Model B tests for the effects of single reporting quarters within the pandemic period 2020Q1 - 2021Q2:

$$
\log _{e} d_{i, t}-\Omega \log _{e} d_{i, t-1}=\alpha_{i}+\sum_{k=1}^{6} \beta_{k} \delta_{i, k}+\epsilon_{i t}
$$

Model C tests for the effects of the pandemic period 2020Q1 - 2021Q2 as a whole, and includes changes in GDP as an additional explanatory variable:

$$
\log _{e} d_{i, t}-\Omega \log _{e} d_{i, t-1}=\alpha_{i}+\beta \delta_{i}^{\{t \geq 2020 Q 1\}}+\rho \log _{e} G D P_{i, t}+\epsilon_{i t}
$$

Model D tests for the effects of single reporting quarters within the pandemic period 2020Q1 - 2021Q2, and includes changes in GDP as an additional explanatory variable:

$$
\log _{e} d_{i, t}-\Omega \log _{e} d_{i, t-1}=\alpha_{i}+\sum_{k=1}^{6} \beta_{k} \delta_{i, k}+\rho \log _{e} G D P_{i, t}+\epsilon_{i t}
$$

Model E tests for the effects of the pandemic period 2020Q1 - 2021Q2 as a whole, and includes the severity of lockdowns as an additional explanatory variable:

$$
\log _{e} d_{i, t}-\Omega \log _{e} d_{i, t-1}=\alpha_{i}+\beta \delta_{i}^{\{t \geq 2020 Q 1\}}+\zeta_{1} F L_{i, t}+\zeta_{2} P L_{i, t}+\epsilon_{i t}
$$

\subsection{Model results}

The models throughout offer a means to test for statistically significant changes in the growth rate of covered deposits throughout the pandemic. Models A and B do so exclusively, without including any other explanatory variables. Of interest is the beta parameter for the overall pandemic period and the $\beta_{k}$ 's $(\mathrm{k} \neq 0)$ for the single quarters within that period. These coefficients correspond to the average percentage point increase in the quarterly growth rate of covered deposits occurring during the respective COVID-19 period partition.

\footnotetext{
${ }^{16}$ Fixed effect and residual variation assumptions are identical for all models explored in this paper.
} 


\begin{tabular}{|c|c|c|c|}
\hline \multicolumn{4}{|c|}{ TABLE TWO: EFFECT SIZES FOR EACH } \\
COVID-19 PERIOD PARTITION \\
\hline \multirow{2}{*}{ Model } & Time period & Effect size (ppt) & Significant effect? \\
\hline A & 2020 Q1-2021Q2 & 1.5 & $\checkmark$ \\
\hline \multirow{2}{*}{ B } & 2020 Q1 & 0.4 & $\mathbf{X}$ \\
\cline { 2 - 4 } & $2020 \mathrm{Q} 2$ & 0.5 & $\mathbf{X}$ \\
\cline { 2 - 4 } & $2020 \mathrm{Q} 3$ & 4.5 & $\checkmark$ \\
\cline { 2 - 4 } & $2020 \mathrm{Q} 4$ & 6.2 & $\mathbf{X}$ \\
\cline { 2 - 4 } & $2021 \mathrm{Q} 1$ & 0.3 & $\mathbf{X}$ \\
\hline
\end{tabular}

Results in model A suggest that the advent of COVID-19 has led to a level shift upwards of the average quarterly growth rate in covered deposits of 1.5 percentage points, above pre-pandemic levels. Importantly, this is a statement about correlation rather than causation. There are a multitude of other factors that also changed as a result of COVID-19 which may (or may not) have had stronger causal influences on the growth rate of covered deposits.

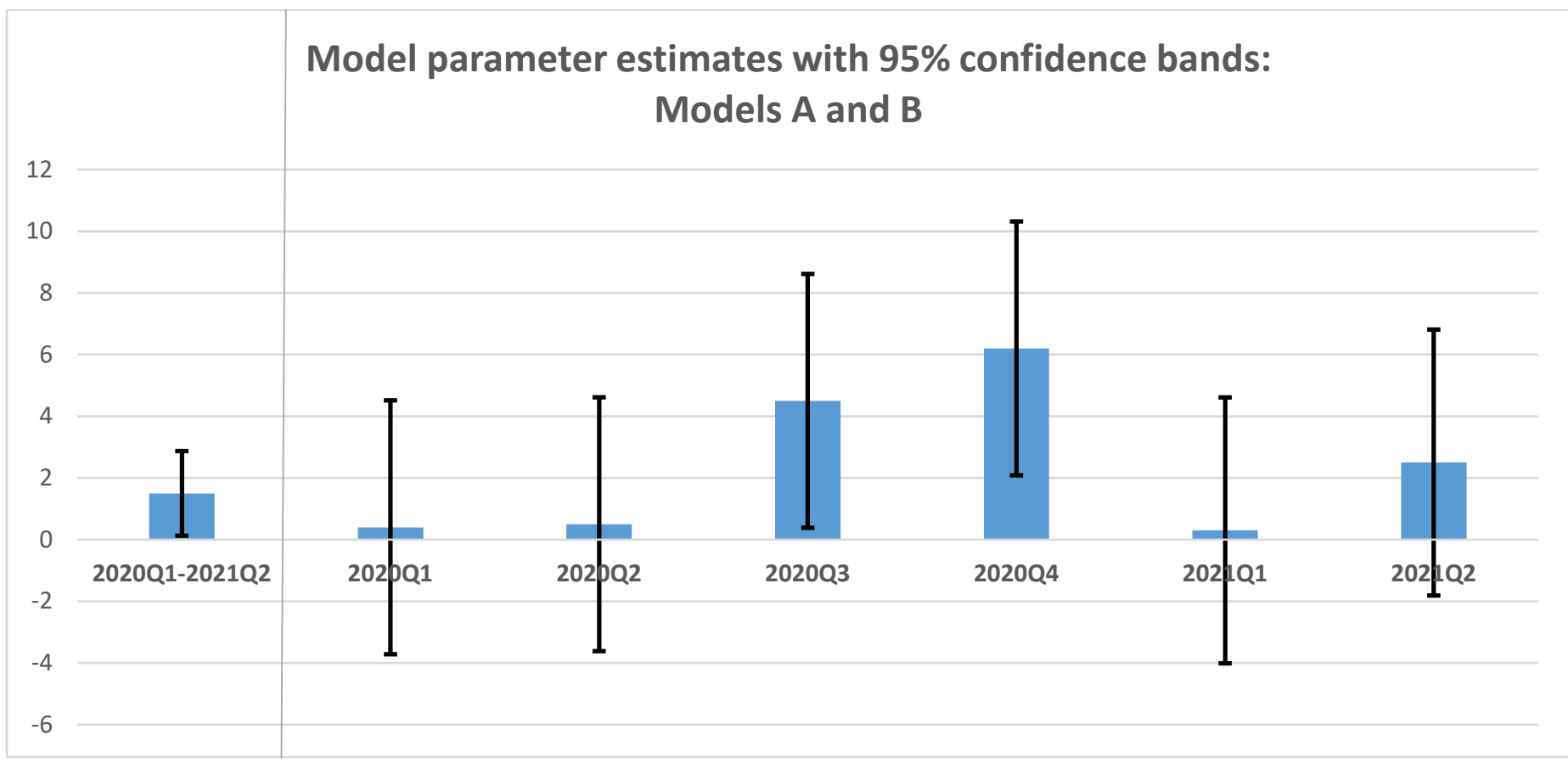

Concerning the six quarterly partitions, all correspond to increases in the growth rate, but only 2020Q3 and 2020Q4 are statistically significant in model $\mathrm{B}$. This seems to point at lagged effects resulting from economic disruption and reduced social mobility (due to lockdowns and other constraints on movement) already introduced as of $2020 \mathrm{Q} 1 .{ }^{17}$ For instance, reduced demand may enable existing inventories to buffer supply chain concerns temporarily before the full consequences are faced by businesses, and eventually consumers. ${ }^{18}$

\footnotetext{
${ }^{17}$ Lagged effects are often fundamental to policy decision making. Ellis (2018) offers an insightful and succinct overview of related issues from the perspective of central banking.

${ }^{18}$ However, the converse is also possible whereby "just in time" inventory systems have driven down inventory levels at the same time that demand is being reduced.
} 
Models $\mathrm{C}, \mathrm{D}$ and $\mathrm{E}$ did not yield any additional statistically significant parameters. This suggests that neither gross domestic product (as a measure of aggregate economic activity) nor full and/or partial lockdowns (as defined in the survey questionnaire) correlate with the growth rate of covered deposits above and beyond that already captured by the quarterly time partitions aforementioned. Such a result indicates that other factors drove the observed changes in covered deposits. Future research may seek to identify such factors - e.g. available household income ${ }^{19}$-, and to isolate and quantify their impact. Table Three in the Appendix presents additional detail on the models explored in this paper.

\subsection{Constraints and limitations}

Like any model, there are constraints on what can be asserted due to assumptions and abstraction from reality. Analysis is also limited by data collected. Many (some potentially very interesting) questions cannot easily be answered via this framework using the data currently available. ${ }^{20}$ Some issues not addressed include:

Substitution effects. Are some of the metrics explored in this paper influenced by substitution effects? COVID-19 (and associated movement restrictions) have provided a platform for global e-commence to jump ${ }^{21}$, with many consumers shifting their shopping habits to online vendors and abandoning 'bricks and mortar' shopping. If so, such new consumption patterns may impact on the correlation between lockdown restrictions and deposits.

Equity markets. Are investors reducing excess deposits by shifting into equity markets seeking yields? Any exploration of this issue requires high frequency data that can adequately represent the dynamic nature of such investor behaviour in quickly adapting markets.

Pent-up demand. Is there evidence of pent-up demand that will run down deposits in a post-COVID world where deferred consumption is realised? Some commentators have suggested that restrictions on service industries such as international travel may result in the airline and hotel industry falling into this category, driving a probable K-shaped recovery ${ }^{22}$ in a significant number of jurisdictions. This hypothesis are not necessarily limited to the services sector. ${ }^{23}$

Each of these issues, along with countless others may form a conceptual basis for extending the analysis in future research activities. This would likely involve collecting further information from key stakeholders and re-specifying models.

\section{Concluding remarks}

A major area of concern for deposit insurers is managing the risks associated with COVID-19. This study investigates quarterly growth rates of covered deposits and finds statistically significant evidence that during the first six quarters of the pandemic, quarterly growth of covered deposits has shifted upwards by $1.5 \%$-points on average, mirroring growth in total deposit. On a per-quarter basis, we find proof for significant increases in the second half of 2020 only. Further analysis in future work will undoubtedly uncover additional insights for policymakers. A key question going forward for deposit insurers is to what extent the increase in savings and covered deposits will continue or reverse itself once the economic recovery from the impact of the pandemic becomes more sustained.

\footnotetext{
${ }^{19}$ See The Economist (2022) for an overview of the variety in which degree governments have compensated households for losses in labour income.

${ }^{20}$ There are also challenges around mapping to the target population. While the research would like to infer about all global jurisdictions, not all have explicit deposit insurance systems, not all are IADI members, and not all have chosen to participate in this survey. Weighting strategies are available to attempt to mitigate sampling and differential non-response issues, but these are beyond this paper's scope.

${ }^{21}$ UNCTAD (2021)

${ }^{22}$ A K-shaped recovery is an economic recovery following a recession where only certain sectors, industries, or areas of the economy recover while others persistently lag.

${ }^{23}$ FDIC (2021)
} 


\section{References}

BCBS. (2021). Basel Committee's reforms helped cushion the impact of Covid-19 shock on banks. Basel Committee for Banking Supervision Press Release.

Croissant, Y. (2020). pglm: Panel Generalized Linear Models. $R$ package version 0.2-2. https://CRAN.Rproject.org/package $=$ pglm

Defina, R. (2021). Impact of the COVID-19 Pandemic on Deposit Insurance. International Association of Deposit Insurers Survey Brief, No. 1.

Ellis, L. (2018). On Lags. Sir Leslie Melville Memorial Lecture, Australian National University.

FDIC. (2021). FDIC Quarterly Banking Profile. Federal Deposit Insurance Corporation publication.

FSB. (2021). Lessons learnt from the COVID-19 pandemic from a financial stability perspective. Financial Stability Board interim report.

Rees, D., Rungcharoenkitkul, P. (2021). Bottlenecks: causes and macroeconomic implications. Bank for International Settlements Bulletin, No. 48.

The Economist. (2022). Winners and losers - Which economies have done best and worst during the pandemic? Jan $1^{\text {st }}$ 2022 edition.

UNCTAD. (2021). Global e-commerce jumps to $\$ 26.7$ trillion, COVID-19 boosts online sales. United Nations Conference on Trade and Development report.

Van Roosebeke, B., Defina, R. (2021). Five Emerging Issues in Deposit Insurance. International Association of Deposit Insurers Policy Brief, No. 4.

World Bank. (2021). The Global Economy: on Track for Strong but Uneven Growth as COVID-19 Still Weighs. World Bank Feature Story. 


\section{Appendix}

Sample composition graphs

Respondents to the survey are compared to those that participated in the 2020 IADI Annual Survey to ascertain how representative they are of the global deposit insurance community. In terms of DI mandate, the survey tends to overrepresent loss minimisers and under-represent payboxes. Similarly, European deposit insurers are over-represented in the sample compared to the 2020 IADI Annual Survey.

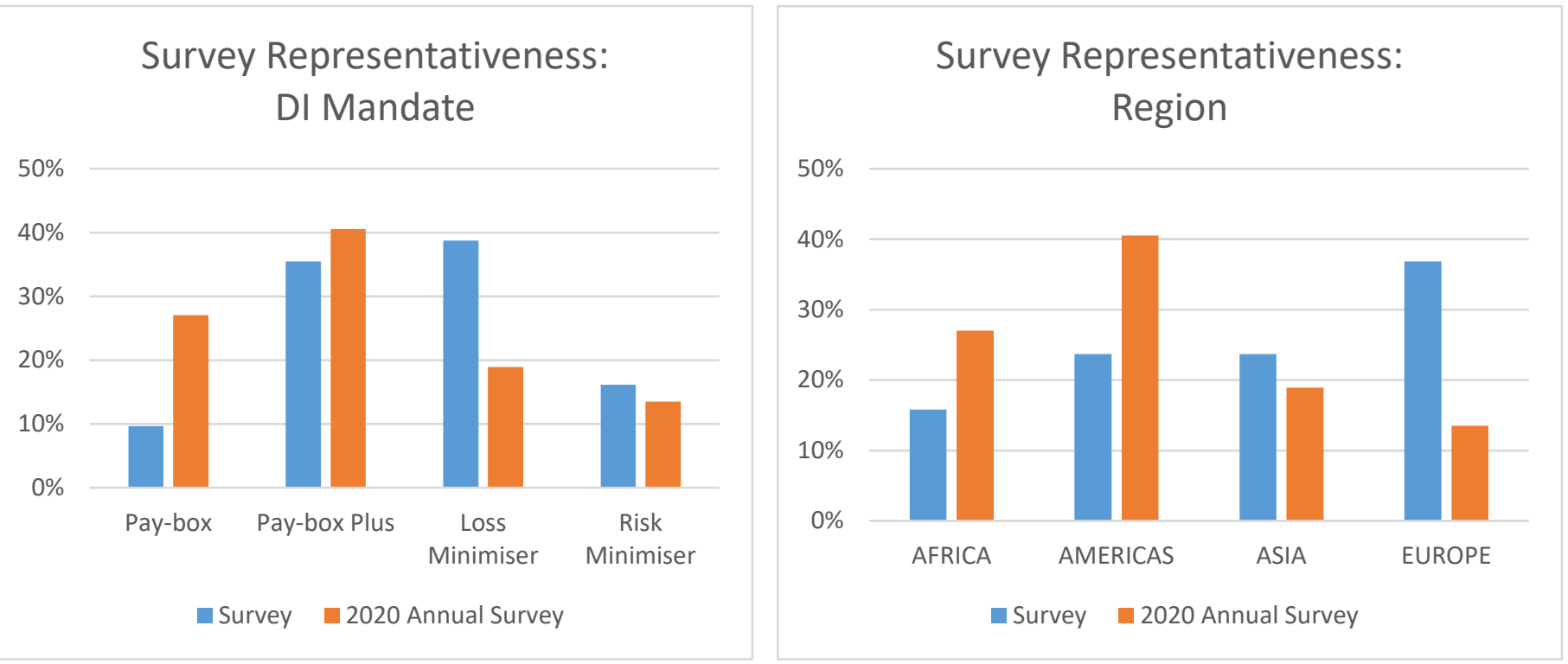

Full model diagnostics

TABLE THREE: FULL MODEL DIAGNOSTICS - ESTIMATES (STANDARD ERRORS) ${ }^{24}$

\begin{tabular}{|c|c|c|c|c|c|}
\hline Coefficient & Model A & Model B & Model C & Model D & Model E \\
\hline $\boldsymbol{\Omega}$ & $86.9(2.3)^{* * *}$ & $86.9(2.3)^{* * *}$ & $87.3(2.4)^{* * *}$ & $88.4(2.5) * * *$ & $86.8(2.3)^{* * *}$ \\
\hline $\boldsymbol{\beta}$ & $1.5(0.7)^{*}$ & & $1.5(0.7) *$ & & $1.8(1.8)$ \\
\hline $\boldsymbol{\beta}_{\mathbf{1}}$ & & $0.4(2.1)$ & & $1.5(2.2)$ & \\
\hline $\boldsymbol{\beta}_{\mathbf{2}}$ & & $0.5(2.1)$ & & $1.6(2.2)$ & \\
\hline $\boldsymbol{\beta}_{\mathbf{3}}$ & & $4.5(2.1)^{*}$ & & $5.5(2.2) *$ & \\
\hline $\boldsymbol{\beta}_{\mathbf{4}}$ & & $6.2(2.1)^{* *}$ & & $7.2(2.2) * *$ & \\
\hline $\boldsymbol{\beta}_{\mathbf{5}}$ & & $0.3(2.2)$ & & $-1.0(2.3)$ & \\
\hline $\boldsymbol{\beta}_{\mathbf{6}}$ & & $2.5(2.2)$ & & $1.2(2.3)$ & \\
\hline $\boldsymbol{\rho}$ & & & $-14.1(14.9)$ & $-33.4(18.6)$ & \\
\hline $\boldsymbol{\zeta}_{\mathbf{1}}$ & & & & & $-0.8(2.3)$ \\
\hline $\boldsymbol{\zeta}_{\mathbf{2}}$ & & & & & $2.0(2.2)$ \\
\hline
\end{tabular}

${ }^{24}$ Figures expressed in percentage points to one decimal place e.g. a coefficient estimate of 0.0525 will be expressed as 5.3 in the table.

$*, * *, * * *$ indicate statistical significance at the $0.05,0.01$ and 0.001 level respectively. 
Survey questionnaire (selected questions only)

Evolution of deposits

Please provide data for the period starting 2017 on the following types of deposits.

Figures should be specified as a stock measure of bank deposits at your member institutions on a quarterly basis, expressed in local currency (in billion). If no quarterly data is available, the most granular

\begin{tabular}{|c|c|c|c|c|c|c|c|c|c|c|c|c|c|c|c|c|c|c|}
\hline & $\begin{array}{l}\text { Q1 } \\
17\end{array}$ & $\begin{array}{l}\text { Q2 } \\
17\end{array}$ & $\begin{array}{l}\text { Q3 } \\
17\end{array}$ & $\begin{array}{l}\text { Q4 } \\
17\end{array}$ & $\begin{array}{l}\text { Q1 } \\
18\end{array}$ & $\begin{array}{l}\text { Q2 } \\
18\end{array}$ & $\begin{array}{l}\text { Q3 } \\
18\end{array}$ & $\begin{array}{l}\text { Q4 } \\
18\end{array}$ & $\begin{array}{l}\text { Q1 } \\
19\end{array}$ & $\begin{array}{l}\text { Q2 } \\
19\end{array}$ & $\begin{array}{l}\text { Q3 } \\
19\end{array}$ & $\begin{array}{l}\text { Q4 } \\
19\end{array}$ & $\begin{array}{l}\text { Q1 } \\
20\end{array}$ & $\begin{array}{l}\text { Q2 } \\
20\end{array}$ & $\begin{array}{l}\text { Q3 } \\
20\end{array}$ & $\begin{array}{l}\text { Q4 } \\
20\end{array}$ & $\begin{array}{l}\text { Q1 } \\
21\end{array}$ & $\begin{array}{l}\text { Q2 } \\
22\end{array}$ \\
\hline $\begin{array}{ll}\text { Total Deposit } \\
\text { Balance }\end{array}$ & & & & & & & & & & & & & & & & & & \\
\hline $\begin{array}{r}\text { Of which: } \\
\text { Eligible }\end{array}$ & & & & & & & & & & & & & & & & & & \\
\hline $\begin{array}{r}\text { Of which: } \\
\text { Covered }\end{array}$ & & & & & & & & & & & & & & & & & & \\
\hline $\begin{array}{l}\text { Total deposits by } \\
\text { Households }\end{array}$ & & & & & & & & & & & & & & & & & & \\
\hline $\begin{array}{r}\text { Of which: } \\
\text { Eligible }\end{array}$ & & & & & & & & & & & & & & & & & & \\
\hline $\begin{array}{l}\text { Of which: } \\
\text { Covered }\end{array}$ & & & & & & & & & & & & & & & & & & \\
\hline $\begin{array}{l}\text { Total deposits by } \\
\text { non-households }\end{array}$ & & & & & & & & & & & & & & & & & & \\
\hline $\begin{array}{r}\text { Of which: } \\
\text { Eligible }\end{array}$ & & & & & & & & & & & & & & & & & & \\
\hline $\begin{array}{r}\text { Of which: } \\
\text { Covered }\end{array}$ & & & & & & & & & & & & & & & & & & \\
\hline $\begin{array}{l}\text { Total deposits by } \\
\text { self-employed }^{\mathbf{2 6}}\end{array}$ & & & & & & & & & & & & & & & & & & \\
\hline $\begin{array}{r}\text { Of which: } \\
\text { Eligible }\end{array}$ & & & & & & & & & & & & & & & & & & \\
\hline
\end{tabular}

${ }^{25}$ This includes, amongst others: Deposits by financial and non-financial corporates and the public sector

${ }^{26}$ Only when non already included in non-household deposits 


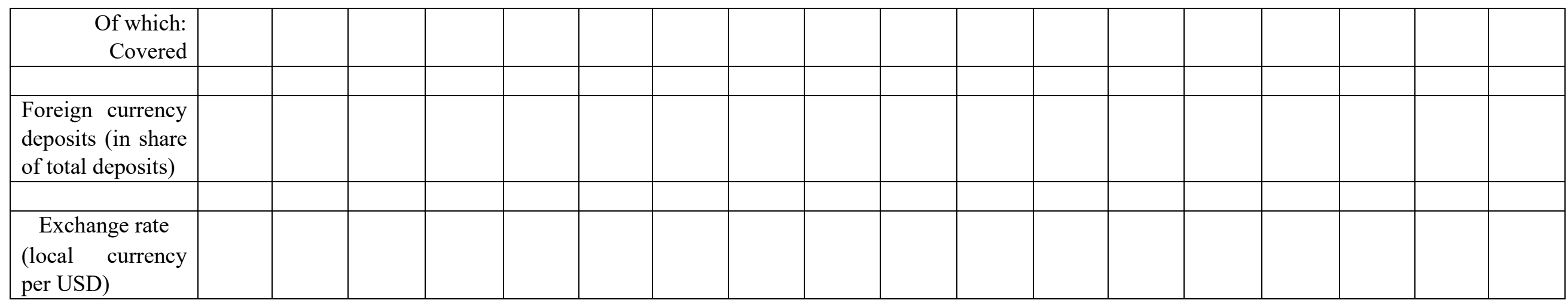

[Please give a short analytical overview of developments in deposits, including on the dominant currencies in foreign currency deposits]

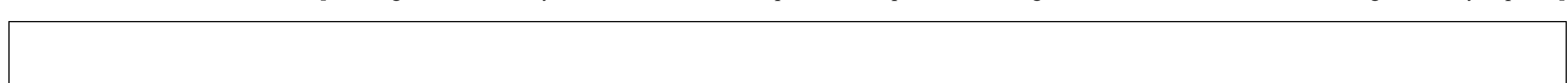




\section{Lockdown Data}

Please select one option for each quarter-year specified. If two options are applicable, only select the one that spanned most of the relevant quarter.

Full / substantial lockdown - Legal requirement for most of the population to stay at home and to leave only on an exceptional basis, e.g. seeking medical treatment, to purchase essential goods, etc.

Partial lockdown - Legal requirement for some sectors to not operate (e.g. non-essential businesses) and/or imposition of other significant constraints on commerce domestically.

No significant lockdown - Most of the economy is able to function as usual, with some accommodations made e.g. mask and/or vaccine requirements.

\begin{tabular}{|c|l|l|l|}
\hline Quarter-Year & Full / substantial lockdown & Partial lockdown & No significant lockdown \\
\hline Q1-20 & & & \\
\hline Q2-20 & & & \\
\hline Q3-20 & & & \\
\hline Q4-20 & & & \\
\hline Q1-21 & & & \\
\hline Q2-21 & & & \\
\hline Q3-21 & & & \\
\hline Q4-21(expected) & & & \\
\hline
\end{tabular}

